\title{
Predictive factors of pathologic complete response in HER2- positive and axillary lymph node positive breast cancer after neoadjuvant paclitaxel, carboplatin plus with trastuzumab
}

\author{
Jinhua Ding ${ }^{1,2, *}$, Yinlong Yang ${ }^{2, *}$, Li Jiang ${ }^{3}$, Weizhu $\mathbf{W u}^{1}$ and Zhiming Shao ${ }^{2}$ \\ ${ }^{1}$ Department of Breast and Thyroid Surgery, Ningbo Medical Center Lihuili Eastern Hospital, Ningbo, China \\ ${ }^{2}$ Department of Breast Surgery, Cancer Center and Cancer Institute, Shanghai Medical College, Fudan University, Shanghai, China \\ ${ }^{3}$ Department of Emergency, Ningbo Medical Center Lihuili Eastern Hospital, Ningbo, China \\ *These authors contributed equally to this work
}

Correspondence to: Weizhu Wu, email: 1144184462@qq.com

Keywords: breast cancer, neoadjuvant chemotherapy, human epidermal growth factor receptor 2 (HER2), Ki67, pathological complete response $(p C R)$

Received: November 11, 2016

Accepted: April 17, 2017

Published: May 19, 2017

Copyright: Ding et al. This is an open-access article distributed under the terms of the Creative Commons Attribution License 3.0 (CC BY 3.0 ), which permits unrestricted use, distribution, and reproduction in any medium, provided the original author and source are credited.

\section{ABSTRACT}

Objective: This study was performed to investigate the proportion as well as the predictive factors of pathologic complete response in HER2-positive and axillary lymph node positive breast cancer after neoadjuvant paclitaxel, carboplatin plus with trastuzumab (PCH).

Results: The pCR rate in the breast, axilla and both was $44.3 \%(39 / 88), 47.7 \%$ $(42 / 88)$ and $34.1 \%(30 / 88)$, respectively. Patients with and without pCR were similar in term of age, BMI, menstrual status, family history, treatment cycles and tumor characteristics (laterality and size of tumor). Multivariate logistic regression demonstrated that pCR was significantly associated with HR negativity (HR $=5.587,95 \%$ CI 2.25-3.889, $p<0.001)$, high Ki67 index (HR = 4.130, 95\% CI 1.607-10.610, $p=0.003)$. Further investigation found that patients with HR-negative/high Ki67 index had higher pCR rate, compared to other patients (HR = 7.583, 95\% CI 2.503-22.974, $p<0.001)$.

Materials and Methods: 88 consecutive Chinese HER2-positive/axillary lymph node-positive breast cancer patients with neodjuvant therapy regimen containing paclitaxel, carboplatin and trastuzumab were divided into two groups: pathological complete response ( $P C R$ ) or non-pCR group. Clinico-pathological characteristics were compared and analyzed, and univariate and multivariate analyses were performed to detect the predictive factors of PCR.

Conclusions: Preoperative PCH regimen was an effective neoadjuvant therapy in HER2 positive and axillary lymph node positive patients, and patients coexisting with HR-negative and high Ki67 index may benefit more from this regimen.

\section{INTRODUCTION}

Amplification of HER2 is identified in approximately $20-25 \%$ of human breast cancers $[1,2]$. The combination of a chemotherapeutic regimen and a recombinant monoclonal antibody against HER2, trastuzumab, has formed the cornerstone of therapy for HER2-positive breast cancer. The superiority of the addition of trastuzumab to a taxane-based chemotherapy regimen is supported by data from metastatic, neoadjuvant and adjuvant studies [3-5]. However, the pCR rate of neoadjuvant chemotherapy (NAC) using taxanes and trastuzumab was not high, ranging from 20 to $40 \%$ in early studies [6, 7]. Carboplatin, instead of anthracyclines, has also been implemented to NAC regimens in an attempt to obtain a higher pCR rate, and indeed, this regimen containing taxane, carboplatin and trastuzumab has been confirmed to be effective in HER2 positive disease [8-10].

However, compared to lymph node negative breast cancer, tumor with HER2 positive and lymph node- 
positive was a subtype of biological and anatomic more aggressive disease. The effectiveness of this regimen used for this type of disease was not established, and the predictive factors of $\mathrm{pCR}$ have not been clarified yet. Thus, in our study, data of patients with HER2-positive and lymph node positive disease, who were treated with carboplatin, paclitaxel concurrently with trastuzumab was retrospectively analyzed, in order to identify effective predictive markers for pCR that could be used in the next future for treatment decision making.

\section{RESULTS}

\section{Patients' characteristics}

Between July 2010 and December 2014, a total of 88 HER2-positive patients with breast cancer were enrolled in the present cohort. Median age was 52 years (ranging from 21 to 71). The proportion of patients aged than 35 years and the opposite was $85.2 \%$ and $14.8 \%$, and that with the status of premenopausal and postmenopausal were $48.9 \%$ and $51.1 \%$.

\section{Neoadjuvant cycles and surgery}

After two cycles of neoadjuvant chemotherapy, 6 patients were transferred to surgery because of SD, and another 6 patients were also transferred to surgery owing to their own willing, despite of CR or PR. After four cycles, another 30 patients were transferred to surgery on account of SD. Finally, 46 patients finished six planned cycles of neoadjuvant chemotherapy.

In spite of high clinical response, the majority of patients still had an obstinate conception that modified radical mastectomy was much safer than breast conserving surgery, so finally only 8 patients received breast conserving surgery. Axillary lymph node clearance were performed in all of 88 patients. Table 1 presents the patients' demographics and clinicopathologic characteristics.

\section{Efficacy evaluation}

Results of clinical response evaluation are also demonstrated (Table 1). There was no PD in 88 eligible patients, and CR, PR, SD were achieved in 20, 62 and 6 patients, respectively. The overall clinical response rate (clinical CR and PR) was 93.2\% (82/88).

As for pathological response, $\mathrm{pCR}$ in the breast was achieved in 39 patients $(44.3 \%)$, in the axilla in 42 patients $(47.7 \%)$, and in both position in 30 patients $(34.1 \%)$. The pathological response evaluation after neoadjuvant treatment is described in Table 2.

\section{Clinicopathological factors of $\mathrm{pCR}$ rate}

Significant clinicopathological factors that affect pCR were identified and compared between the two groups in Table 3 . The pCR was more commonly detected with HR-negativity $(50.0 \%$ vs $18.2 \%, p=0.002)$. The $\mathrm{pCR}$ group showed more cases with high Ki67 index (48.7\% vs $22.4 \%, p=0.013)$.

\section{Predictive factors of $\mathrm{pCR}$ rate}

Multivariate logistic regression analysis including all parameters which were analyzed in univariate analysis showed that HR negativity and high Ki67 index were two independent pCR predictors (Table 4). The hazard ratios for HR negativity and high Ki67 index was 5.587 (95\% CI, 2.257-13.889) and 4.130 (95\% CI, 1.607-10.610), respectively.

\section{pCR rate on subgroups defined by predictive factors}

Correlation analysis shows that $\mathrm{Ki} 67$ index did not correlate to HR status (coefficient was $0.025, p=0.820$ ). Thus, based on the status of HR and Ki67 index, 88 patients were classified into four groups: HR-negative/ low-Ki67-index group $(n=24)$, HR-negative/high-Ki67index group $(n=20)$, HR-positive/low-Ki67-index group $(n=25)$, HR-positive/high-Ki67-index group $(n=19)$.

The pCR rate between subgroups stratified according to HR status and Ki67 index is demonstrated in Table 5. The pCR rate in HR-negative/high-Ki67-index group (70.0\%, $14 / 20)$ was higher than in the other groups $(23.5 \%, 16 / 68)$, the hazard ratio was $7.583(95 \% \mathrm{CI}, 2.503-22.974, p<0.001)$.

\section{DISCUSSION}

To the best of our knowledge, this is the first and sole study to identify the predictive factors for pCR on HER2positive/axillary lymph node positive breast cancer patients receiving neoadjuvant regimen containing paclitaxenl and carboplatin concurrently with trastuzumab. In the present study, we clarified that the NAC regimen with paclitaxenlcarboplatin-trastuzumab was useful for obtaining a $\mathrm{pCR}$ rate of $34.1 \%$. The pCR rate in our study was much lower than in previous reports, in which the similar regimen was adopted and achieved the pCR varying from 44-76\% [8-10]. Significant difference between our study and others must be stated that the cases enrolled in our study were axillary lymph node positive, while the cases in others comprised of both lymph node positive and negative disease. In addition, the majority of tumors in our study were T2 or even higher stage. Both factors may contribute to relative low $\mathrm{pCR}$ rate in our study.

The predictive value of HR status for $\mathrm{pCR}$ after trastuzumab-based neoadjuvant was controversial, though positive results were found in the majority of the studies [11-16]. While, HR status was not demonstrated a predictive factor for $\mathrm{pCR}$ in other studies [17, 18]. In above studies, carboplatin was not contained in 


\begin{tabular}{|c|c|c|}
\hline & $n$ & $\%$ \\
\hline Case number & 88 & \\
\hline Mean age (years) & 52 & \\
\hline \multicolumn{3}{|l|}{ Menstrual status } \\
\hline Premenopause & 43 & 48.9 \\
\hline Postmenopause & 45 & 51.1 \\
\hline \multicolumn{3}{|l|}{ Age } \\
\hline$\leq 35$ years & 13 & 14.8 \\
\hline$>35$ years & 75 & 85.2 \\
\hline \multicolumn{3}{|l|}{ BMI } \\
\hline$\leq 25$ & 54 & 61.4 \\
\hline$>25$ & 34 & 38.6 \\
\hline \multicolumn{3}{|l|}{ Laterality } \\
\hline Left & 50 & 56.8 \\
\hline Right & 38 & 43.2 \\
\hline \multicolumn{3}{|l|}{ Family history } \\
\hline Yes & 6 & 6.8 \\
\hline No & 82 & 93.2 \\
\hline \multicolumn{3}{|l|}{ Number of cycles } \\
\hline$<4$ & 12 & 13.6 \\
\hline$\geq 4$ & 76 & 86.4 \\
\hline \multicolumn{3}{|l|}{ ER status } \\
\hline Negative & 46 & 52.3 \\
\hline Positive & 42 & 47.7 \\
\hline \multicolumn{3}{|l|}{ PR status } \\
\hline Negative & 54 & 61.4 \\
\hline Positive & 34 & 38.6 \\
\hline \multicolumn{3}{|l|}{ HR status } \\
\hline Negative & 44 & 50.0 \\
\hline Positive & 44 & 50.0 \\
\hline \multicolumn{3}{|l|}{ Ki-67 } \\
\hline High $(>30 \%)$ & 39 & 44.3 \\
\hline Low $(\leq 30 \%)$ & 49 & 55.7 \\
\hline \multicolumn{3}{|l|}{ Primary tumor stage } \\
\hline $\mathrm{T} 1$ & 14 & 15.9 \\
\hline $\mathrm{T} 2$ & 59 & 67.0 \\
\hline $\mathrm{T} 3$ & 13 & 14.8 \\
\hline $\mathrm{T} 4$ & 2 & 2.3 \\
\hline \multicolumn{3}{|l|}{ Clinical Response } \\
\hline $\mathrm{CR}$ & 20 & 22.7 \\
\hline PR & 62 & 70.5 \\
\hline SD & 6 & 6.8 \\
\hline $\mathrm{PD}$ & 0 & 0 \\
\hline \multicolumn{3}{|l|}{ Surgery type } \\
\hline Breast conserving surgery & 8 & 9.1 \\
\hline Mastectomy & 80 & 90.9 \\
\hline
\end{tabular}

BMI: body mass index; ER: estrogen receptor; PR: progesterone receptor; HR: hormone receptor; T: tumor; CR: complete response; PR: partial response; SD: stable disease; PD: progression of disease. 


\begin{tabular}{lcc}
\hline Category & $\boldsymbol{N}$ & \% \\
\hline Pathological tumor category & 37 & 42.0 \\
ypT0 & 2 & 2.3 \\
ypTis & 22 & 25.0 \\
ypT1 & 24 & 27.3 \\
ypT2 & 3 & 3.4 \\
ypT3 & & \\
Pathological nodal category & 42 & 47.7 \\
ypN0 & 23 & 26.1 \\
ypN1 & 14 & 15.9 \\
ypN2 & 9 & 10.2 \\
ypN3 & & \\
Combination tumor and nodal category & 30 & 34.1 \\
axillary pCR+ / tumor pCR + & 12 & 13.6 \\
axillary pCR+ / tumor pCR- & 9 & 10.2 \\
axillary pCR- / tumor pCR+ & 37 & 42.0 \\
axillary pCR- / tumor pCR- & & \\
\hline
\end{tabular}

pCR: pathologic complete response; T: tumor; N: node.

neoadjuvant regimens. Our study confirmed that HR status was an independent predictive factor for $\mathrm{pCR}$ after neoadjuvant regimen containing paclitaxel, carboplatin and trastuzumab, which has been repetitively reported recently [19-21]. However, the neoadjuvant regimen was different in these studies, including DC-H (docetaxel, carboplatin, trastuzumab) or D-H [19], DC-HP (docetaxel, carboplatin, trastuzumab, pertuzumab) [20], PC-H (paclitaxel, carboplatin, trastuzumab [21].

The second independent predictive factor detected in our study was Ki67 index. The Ki67 cut-off point in different studies varied between $5 \%$ and $34 \%$ [22-24], and the ideal cut-off point has not come to a consensus yet. The predictive value was validated in the majority of previous studies [19, 25-29]. However, another retrospective study in which the same neoadjuvant regimen was administrated as that in our study, showed that high Ki67 index was not associated with higher pCR [21].The controversial result between this study and ours may result from the different baseline characteristics of enrolled patient population, because all patients in our study were axillary lymph node positive, while the patients in the other study comprised of both node positive (59.4\%) and node negative (40.6\%) patients.

In our study, further correlation analysis showed that Ki67 did not correlate to HR status, which enabled us to stratify patients into four subgroups based on HR status and Ki67 index: HR-negative/low-Ki67-index, HR-negative/high-Ki67-index, HR-positive/low-Ki67index, HR-positive/high-Ki67-index group. The pCR rate in HR-negative/high-Ki67-index group was significantly higher than the other subgroups (shown in Table 5), suggesting that combination of HR status and Ki67 index can effectively discriminate patients with differential opportunity of achieving pCR.

The highlight of our study should be recognized. Firstly, patients enrolled in our study were HER2positive invasive breast cancer with lymph node involvement, which was a subtype of biological and anatomic aggressive disease. In addition, the positivity of axillary lymph node was ascertained by fine-needle aspiration before neoadjuvant therapy, which enabled us to evaluate the $\mathrm{pCR}$ in the axillary lymph node after neoadjuvant therapy. Secondly, the neoadjuvant regimen in our study was non-anthracyclines, which can further decrease heart risks. Because chemotherapy drugs, especially anthracyclines can lead to irreversible heart damage, and anti-HER2 drug, trastuzumab may decrease cardiac function in some patients. Thirdly, the neoadjuvant regimen adopted in our study was PCH (paclitaxel, carboplatin and trastuzumab), which was confirmed to be effective on prior studies, and equally effective to EC-PH (epirubicin, cyclophosphamide, followed by paclitaxel and trastuzumab) [8-10]; while in the other study, the majority of patients $(83.3 \%)$ were administered with $\mathrm{DH}$ or $\mathrm{PH}$ (docetaxel or paclitaxel with trastuzumab) regimen, which was applicable for low recurrence risk patients, especially for node negative patients.

Of course, the limitations of the present study also should be acknowledged. First, this was a retrospective, single-institution study with small sample size, which may decrease the reliability of the present study. Second, some parameters, for example, tumor-infiltrating lymphocytes and tumor histological grade before neoadjuvant therapy 
Table 3: Relationship of clinicopathologic factors for PCR

\begin{tabular}{|c|c|c|c|c|c|}
\hline Variabe & $\operatorname{pCR}(n)$ & Non-pCR (n) & $P$ value & Hazard ratio & $95 \%$ CI \\
\hline \multicolumn{6}{|l|}{ Menstrual status } \\
\hline Premenopause & 13 & 30 & 0.455 & 0.714 & $0.294-1.733$ \\
\hline Postmenopause & 17 & 28 & & & \\
\hline \multicolumn{6}{|l|}{ Age } \\
\hline$\leq 35$ years & 4 & 9 & 0.784 & 0.838 & $0.235-2.983$ \\
\hline$>35$ years & 26 & 49 & & & \\
\hline \multicolumn{6}{|l|}{ BMI } \\
\hline$\leq 25$ & 20 & 34 & 0.462 & 1.412 & $0.562-3.548$ \\
\hline$>25$ & 10 & 24 & & & \\
\hline \multicolumn{6}{|l|}{ Laterality } \\
\hline Left & 14 & 36 & 0.167 & 0.535 & $0.219-1.305$ \\
\hline Right & 16 & 22 & & & \\
\hline \multicolumn{6}{|l|}{ Family history } \\
\hline Yes & 3 & 3 & 0.406 & 2.037 & $0.385-10.770$ \\
\hline No & 27 & 55 & & & \\
\hline \multicolumn{6}{|l|}{ Cycles } \\
\hline$<4$ & 4 & 8 & 0.952 & 0.962 & $0.265-3.494$ \\
\hline$\geq 4$ & 26 & 50 & & & \\
\hline \multicolumn{6}{|l|}{ HR status } \\
\hline Negative & 22 & 22 & 0.002 & 4.500 & $1.710-11.841$ \\
\hline Positive & 8 & 36 & & & \\
\hline \multicolumn{6}{|l|}{ Ki-67 } \\
\hline High $(>30 \%)$ & 19 & 20 & 0.013 & 3.282 & $1.309-80227$ \\
\hline Low $(\leq 30 \%)$ & 11 & 38 & & & \\
\hline \multicolumn{6}{|l|}{ T stage } \\
\hline T1-2 & 24 & 49 & 0.596 & 0.735 & $0.234-2.303$ \\
\hline T3-4 & 6 & 9 & & & \\
\hline
\end{tabular}

pCR: pathologic complete response; BMI: body mass index; HR: hormone receptor; T: tumor; CI: confidence interval.

were not provided, which were proven to be predictive factors in other report [21], and could not be further verified in our study. Third, because of the short term follow-up time, survival data are unavailable in the study. Therefore, it is unclear whether the $\mathrm{pCR}$ improvement would transfer to a survival benefit.

\section{MATERIALS AND METHODS}

\section{Patient selection}

Totally 88 HER2-positive breast cancer patients treated with taxane, platinum, trastuzumab preoperatively at Fudan University Shanghai Cancer Center were retrospectively analyzed. Other inclusion criteria included the following: (1) All patients were histologically proven to be invasive ductal carcinoma, (2) At least one axillary lymph node in each patient was proven positive by fine needle aspiration, (3) Status of ER, PR, HER2 and expression of Ki67 were essentially determined before neoadjuvant therapy. Patients either with inflammation breast cancer or with any evidence of distant metastasis were excluded from the study. All patients signed an informed consent before neoadjuvant treatment started.

\section{Evaluation of ER, PR, HER2 and Ki67}

According to the revised version of immunohistochemical testing guideline in 2010, ER and PR assay should be considered positive if immunostaining was seen in more than $1 \%$ tumor nuclei [30]. The criteria of HER2 positivity was defined as either IHC3+ or gene amplification by fluorescence in situ hybridization (FISH) [31]. In the present study, 30\%, the median Ki67 index was used to categorize patients into low Ki67 index group and high Ki67 index group. If a patient had a Ki67 index less or equal to $30 \%$, the patient was considered to have a low Ki67 index, while a patient with a Ki67 index greater to $30 \%$ was considered to have a high Ki67 index.

\section{Treatment details}

The treatment regimen including paclitaxel, carboplatin and trastuzumab (abbreviated as $\mathrm{PCH}$ ) 
Table 4: Multivariate analysis for $\mathrm{PCR}$ predictive parameters

\begin{tabular}{|c|c|c|c|c|c|}
\hline Variable & $\operatorname{pCR}(n)$ & Non-pCR (n) & $P$ value & Hazard ratio & $95 \%$ CI \\
\hline \multicolumn{6}{|l|}{ Menstrual status } \\
\hline Premenopause & 13 & 30 & 0.191 & 2.391 & $0.647-8.831$ \\
\hline Postmenopause & 17 & 28 & & & \\
\hline \multicolumn{6}{|l|}{ Age } \\
\hline$\leq 35$ years & 4 & 9 & 0.131 & 4.168 & $0.655-26.532$ \\
\hline$>35$ years & 26 & 49 & & & \\
\hline \multicolumn{6}{|l|}{ BMI } \\
\hline$\leq 25$ & 20 & 34 & 0.432 & 1.558 & $0.516-4.708$ \\
\hline$>25$ & 10 & 24 & & & \\
\hline \multicolumn{6}{|l|}{ Laterality } \\
\hline Left & 14 & 36 & 0.121 & 2.035 & $0.830-4.993$ \\
\hline Right & 16 & 22 & & & \\
\hline \multicolumn{6}{|l|}{ Family history } \\
\hline Yes & 3 & 3 & 0.086 & 0.441 & $0.173-1.123$ \\
\hline No & 27 & 55 & & & \\
\hline \multicolumn{6}{|l|}{ Cycles } \\
\hline$<4$ & 4 & 8 & 0.897 & 1.102 & $0.253-4.806$ \\
\hline$\geq 4$ & 26 & 50 & & & \\
\hline \multicolumn{6}{|l|}{ HR status } \\
\hline Negative & 22 & 22 & $<0.001$ & 5.587 & $2.257-13.889$ \\
\hline Positive & 8 & 36 & & & \\
\hline \multicolumn{6}{|l|}{ Ki-67 } \\
\hline High (> 30\%) & 19 & 20 & 0.003 & 4.130 & $1.607-10.610$ \\
\hline Low $(\leq 30 \%)$ & 11 & 38 & & & \\
\hline \multicolumn{6}{|l|}{ T stage } \\
\hline T1-2 & 24 & 49 & 0.780 & 0.850 & $0.272-2.659$ \\
\hline $\mathrm{T} 3-4$ & 6 & 9 & & & \\
\hline
\end{tabular}

pCR: pathologic complete response; BMI: body mass index; HR: hormone receptor; T: tumor; CI: confidence interval.

Table 5: Comparison of pCR rate between groups defined by hormonal receptor and Ki67

\begin{tabular}{cccccc}
\hline Group & Definition & Case number & pCR $(\boldsymbol{n})$ & Non-pCR $(\boldsymbol{n})$ & pCR $(\%)$ \\
\hline 1 & HR negative and low Ki67 index & 24 & 8 & 16 & 33.3 \\
$2^{*}$ & HR negative and high Ki67 index & 20 & 14 & 6 & 70.0 \\
3 & HR positive and low Ki67 index & 25 & 3 & 22 & 12.0 \\
4 & HR positive and high Ki67 index & 19 & 5 & 14 & 26.3 \\
\hline
\end{tabular}

* Group 2 was compared with the combination of Group 1 + Group 3 + Group 4.

$p<0.001, \mathrm{HR}=7.583,95 \% \mathrm{CI}, 2.503-22.974$.

were administrated to 83 patients. The remaining 5 patients received the equivalent of $\mathrm{PCH}$ regimen, with nab-paclitaxel instead of paclitaxel in 2 patients and cisplatinum instead of carboplatin in 3 patients, in whom the count of blood platelet was less than 80 billions per litre, and carboplatin using may further decrease the count of the platelet. Treatment cycles were decided by physicians according to the outcome of clinical response evaluation at every two cycles. Six cycles were planned for patients in whom tumor response evaluation was clinical effective, including complete response and partial response. While, the evaluation of stable disease or progression of disease always led to the termination of neoadjuvant therapy and surgery could be performed afterwards.

Breast surgery including extended lumpectomy and axillary lymph node clearance were performed at 2-4 weeks after the last dose. As it should be, trastuzumab with duration of one year in total was recommended for all patients. In addition, adjuvant radiotherapy and endocrine therapy were administered in appropriate patients according to current available clinical practice guideline. 


\section{Data collection}

The following data was collected, including: patient's demographics (age, menstrual status, BMI, family history defined as there is one or more breast cancer sufferers in a patient's first or second relatives), pre-treatment tumor characteristics (tumor size, tumor laterality and status of ER, PR, HER2, Ki67 expression), treatment details (drug, dose, cycles, side effect), clinical and pathological response evaluation after neoadjuvant therapy.

Clinical response in the breast and axilla were evaluated using breast ultrasound. Clinical response was categorized as the following: complete response (CR), partial response (PR), stable disease (SD), and progression of disease (PD) [6]. pCR in the breast was defined as disappearance of residual invasive disease (residual ductal carcinoma in situ allowed) in the breast by pathologic examination, and $\mathrm{pCR}$ in the axilla was defined as the absence of positive lymph node by hematoxylin and eosin staining.

\section{Statistical analysis}

Univariate analysis with chi-squared test or Fisher's exact test was performed to detect predictors for pCR. Multivariate analysis was performed to test factors' independence by logistic regression analysis. Statistical significance was defined as $p<0.05$, and hazard ratio (HR) and $95 \%$ confidence intervals $(\mathrm{CI})$ were also calculated. All statistical tests were two-sided, and all analyses were performed using SPSS v.19.0 software (SPSS, Chicago, IL, http://www.spss.com).

\section{CONCLUSIONS}

In summary, our study shows that HR negativity and high Ki67 index are two independent factors for predicting higher pCR in HER2-positive/axillary lymph node positive breast cancer. Especially in patients with HR-negative/high-Ki67-index, the pCR rate even reached $70.0 \%$, suggesting that such patient population may achieve more benefit from neoadjuvant therapy containing paclitaxel, carboplatin and trastuzumab.

\section{Abbreviations}

HER2: human epidermal growth factor receptor 2; pCR: pathologic complete response; NAC: neoadjuvant chemotherapy; BMI: body mass index; ER: estrogen receptor; PR: progesterone receptor; HR: hormone receptor; CR: complete response; PR: partial response; SD: stable disease; PD: progression of disease; HR: hazard ratio; CI: confidence intervals.

\section{Authors' contributions}

JHD and YLY conceived of and designed the study. JHD and ZMS performed the analyses. YLY and LJ prepared all tables. JHD, YLY, and WZW wrote the main manuscript. All authors reviewed the manuscript.

\section{CONFLICTS OF INTEREST}

All authors declared that they have no competing interests.

\section{GRANT SUPPORT}

This study was supported by grants from Ningbo Science and Technology Bureau (No. 2015C50003).

\section{REFERENCES}

1. Owens MA, Horten BC, Da Silva MM. HER2 amplification ratios by fluorescence in situ hybridization and correlation with immunohistochemistry in a cohort of 6556 breast cancer tissues. Clin Breast Cancer. 2004; 5:63-69.

2. Slamon DJ, Clark GM, Wong SG, Levin WJ, Ullrich A, McGuire WL. Human breast cancer: correlation of relapse and survival with amplification of the HER-2/neu oncogene. Science. 1987; 235:177-182.

3. Piccart-Gebhart MJ, Procter M, Leyland-Jones B, Goldhirsch A, Untch M, Smith I, Gianni L, Baselga J, Bell R, Jackisch C, Cameron D, Dowsett M, Barrios CH, et al. Herceptin Adjuvant (HERA) Trial Study Team Trastuzumab after adjuvant chemotherapy in HER2-positive breast cancer. N Engl J Med. 2005; 353:1659-1672.

4. Slamon D, Eiermann W, Robert N, Pienkowski T, Martin M, Press M, Mackey J, Glaspy J, Chan A, Pawlicki M, Pinter T, Valero V, Liu MC, et al. Breast Cancer International Research Group. Adjuvant trastuzumab in HER2-positive breast cancer. N Engl J Med. 2011; 365:1273-1283.

5. Gianni L, Eiermann W, Semiglazov V, Manikhas A, Lluch A, Tjulandin S, Zambetti M, Vazquez F, Byakhow M, Lichinitser M, Climent MA, Ciruelos E, Ojeda B, et al. Neoadjuvant chemotherapy with trastuzumab followed by adjuvant trastuzumab versus neoadjuvant chemotherapy alone, in patients with HER2-positive locally advanced breast cancer (the NOAH trial): a randomised controlled superiority trial with a parallel HER2-negative cohort. Lancet. 2010; 375:377-384.

6. Burstein HJ, Harris LN, Gelman R, Lester SC, Nunes RA, Kaelin CM, Parker LM, Ellisen LW, Kuter I, Gadd MA, Christian RL, Kennedy PR, Borges VF, et al. Preoperative therapy with trastuzumab and paclitaxel followed by sequential adjuvant doxorubicin/cyclophosphamide for HER2 overexpressing stage II or III breast cancer: a pilot study. J Clin Oncol. 2003; 21:46-53.

7. Limentani SA, Brufsky AM, Erban JK, Jahanzeb M, Lewis D. Phase II study of neoadjuvant docetaxel, vinorelbine, and trastuzumab followed by surgery and adjuvant doxorubicin plus cyclophosphamide in women with human epidermal growth factor receptor 
2-overexpressing locally advanced breast cancer. J Clin Oncol. 2007; 25:1232-1238.

8. Sikov WM, Dizon DS, Strenger R, Legare RD, Theall KP, Graves TA, Gass JS, Kennedy TA, Fenton MA. Frequent pathologic complete responses in aggressive stages II to III breast cancers with every-4-week carboplatin and weekly paclitaxel with or without trastuzumab: A Brown University Oncology Group Study. J Clin Oncol. 2009; 27:4693-4700.

9. Yu KD, Liu GY, Chen CM, Li JW, Wu J, Lu JS, Shen ZZ, Shao ZM. Weekly Paclitaxel/Carboplatin/ Trastuzumab Therapy Improves Pathologic Complete Remission in Aggressive HER2-Positive Breast Cancers, Especially in Luminal-B Subtype, Compared With a Once-Every-3Weeks Schedule. The Oncologist. 2013; 18:511-517.

10. Sonke GS, Mandjes IA, Holtkamp MJ, Schot M, van Werkhoven E, Wesseling J, Vrancken Peeters MJ, Rodenhuis S, Linn SC. Paclitaxel, carboplatin, and trastuzumab in a neo-adjuvant regimen for HER2-positive breast cancer. Breast J. 2013; 19:419-426.

11. Buzdar AU, Ibrahim NK, Francis D, Booser DJ, Thomas ES, Theriault RL, Pusztai L, Green MC, Arun BK, Giordano SH, Cristofanilli M, Frye DK, Smith TL, et al. Significantly higher pathologic complete remission rate after neoadjuvant therapy with trastuzumab, paclitaxel, and epirubicin chemotherapy: results of a randomized trial in human epidermal growth factor receptor 2-positive operable breast cancer. J Clin Oncol. 2005; 23:3676-3685.

12. Gianni L, Eiermann W, Semiglazov V, Manikhas A, Lluch A, Tjulandin S, Zambetti M, Vazquez F, Byakhow M, Lichinitser M, Climent MA, Ciruelos E, Ojeda B, et al. Neoadjuvant chemotherapy with trastuzumab followed by adjuvant trastuzumab versus neoadjuvant chemotherapy alone, in patients with HER2-positive locally advanced breast cancer (the NOAH trial): a randomised controlled superiority trial with a parallel HER2-negative cohort. Lancet. 2010; 375:377-384.

13. Baselga J, Bradbury I, Eidtmann H, Di Cosimo S, de Azambuja E, Aura C, Gómez H, Dinh P, Fauria K, Van Dooren V, Aktan G, Goldhirsch A, Chang TW, et al. NeoALTTO Study Team.Lapatinib with trastuzumab for HER2-positive early breast cancer (NeoALTTO): a randomised, open-label, multicentre, phase 3 trial. Lancet. 2012; 379:633-640.

14. Gianni L, Pienkowski T, Im YH, Roman L, Tseng LM, Liu MC, Lluch A, Staroslawska E, de la Haba-Rodriguez J, Im SA, Pedrini JL, Poirier B, Morandi P, et al. Efficacy and safety of neoadjuvant pertuzumab and trastuzumab in women with locally advanced, inflammatory, or early HER2-positive breast cancer (NeoSphere): a randomised multicentre, open-label, phase 2 trial. Lancet Oncol. 2012; 13:25-32.

15. Robidoux A, Tang G, Rastogi P, Geyer CE Jr, Azar CA, Atkins JN, Fehrenbacher L, Bear HD, Baez-Diaz L, Sarwar S, Margolese RG, Farrar WB, Brufsky AM, et al. Lapatinib as a component of neoadjuvant therapy for
HER2-positive operable breast cancer (NSABP protocol B-41): an open-label, randomised phase 3 trial. Lancet Oncol. 2013; 14:1183-1192.

16. Untch M, Rezai M, Loibl S, Fasching PA, Huober J, Tesch H, Bauerfeind I, Hilfrich J, Eidtmann H, Gerber B, Hanusch C, Kühn T, du Bois A, et al. Neoadjuvant treatment with trastuzumab in HER2-positive breast cancer: results from the GeparQuattro study. J Clin Oncol. 2010; 28:2024-2031.

17. Untch M, Fasching PA, Konecny GE, Hasmüller S, Lebeau A, Kreienberg R, Camara O, Müller V, du Bois A, Kühn T, Stickeler E, Harbeck N, Höss C, et al. Pathologic complete response after neoadjuvant chemotherapy plus trastuzumab predicts favorable survival in human epidermal growth factor receptor 2-overexpressing breast cancer: results from the TECHNO trial of the AGO and GBG study groups. J Clin Oncol. 2011; 29:3351-3357.

18. Kurozumi $\mathrm{S}$, Inoue $\mathrm{K}$, Takei $\mathrm{H}$, Matsumoto $\mathrm{H}$, Kurosumi M, Horiguchi J, Takeyoshi I, Oyama T. ER, $\mathrm{PgR}, \mathrm{Ki67}$, p27Kip1, and histological grade as predictors of pathological complete response in patients with HER2positive breast cancer receiving neoadjuvant chemotherapy using taxanes followed by fluorouracil, epirubicin, and cyclophosphamide concomitant with trastuzumab. BMC Cancer. 2015; 15:622-629.

19. Zhang GC, Qian XK, Guo ZB, Ren CY, Yao M, Li XR, Wang K, Zu J, Liao N. Pre-treatment hormal receptor status and Ki67 index predict pathological complete response to neoadjuvant trastuzumab/taxanes but not disease-free survival in HER2-positive breast cancer patients. Med Oncol. 2012; 29:3222-3231.

20. Tiwari SR, Mishra P, Raska P, Calhoun B, Abraham J, Moore H, Budd GT, Fanning A, Valente S, Stewar R, Grobmyer SR, Montero AJ. Retrospective study of the efficacy and safety of neoadjuvant docetaxel, carboplatin, trastuzumab/pertuzumab (TCH-P) in nonmetastatic HER2positive breast cancer. Breast Cancer Res Treat. 2016; 158:189-193.

21. Liu S, Xu L, Zhang H, Zhang S, Li T, Duan X, Liu Y. Predictive factors of pathological complete response in primary human epidermal growth factor receptor 2-positive breast cancer treated with trastuzumab-based neoadjuvant chemotherapy. [Article in Chinese]. Zhonghua Wai Ke Za Zhi. 2016; 54:94-98.

22. Urruticoechea A, Smith IE, Dowsett M. Proliferation marker Ki-67 in early breast cancer. J Clin Oncol. 2005; 23:7212-7220.

23. Goldhirsch A, Wood WC, Coates AS, Gelber RD, Thürlimann B, Senn HJ; Panel members. Strategies for subtypes - dealing withthe diversity of breast cancer: highlights of the St. Gallen International Expert Consensus on the Primary Therapy of Early Breast Cancer 2011. Ann Oncol. 2011; 22:1736-1747.

24. Goldhirsch $\mathrm{A}$, Ingle $\mathrm{JN}$, Gelber $\mathrm{RD}$, Coates $\mathrm{AS}$, Thürlimann B, Senn HJ; Panel members. Thresholds for 
therapies: highlights of the St Gallen International Expert Consensus on the primary therapy of early breast cancer 2009. Ann Oncol. 2009; 20:1319-1329.

25. Fasching PA, Heusinger K, Haeberle L, Niklos M, Hein A, Bayer CM, Rauh C, Schulz-Wendtland R, Bani MR, Schrauder M, Kahmann L, Lux MP, Strehl JD, et al. Ki67, chemotherapy response, and prognosis in breast cancer patients receiving neoadjuvant treatment. BMC Cancer. 2011; 11:486-498.

26. Houssami N, Macaskill $P$, von Minckwitz G, Marinovich ML, Mamounas E. Meta-analysis of the association of breast cancer subtype and pathologic complete response to neoadjuvant chemotherapy. Eur J Cancer. 2012; 48:3342-3354.

27. Luporsi E, André F, Spyratos F, Martin PM, Jacquemier J, Penault-Llorca F, Tubiana-Mathieu N, Sigal-Zafrani B, Arnould L, Gompel A, Egele C, Poulet B,Clough KB, et al. Ki-67: level of evidence and methodoligical considerations for its role in the clinical management of breast cancer: analytical and critical review. Breast Cancer Res Treat. 2012; 132:895-915.

28. Sánchez-Muñoz A, Navarro-Perez V, Plata-Fernández Y, Santonja A, Moreno I, Ribelles N, Alba E. Proliferation Determined by Ki-67 Defines Different Pathologic Response to Neoadjuvant Trastuzumab-Based Chemotherapy in HER2-Positive Breast Cancer. Clin Breast Cancer. 2015; 15:343-347.

29. Bozzetti C, Musolino A, Camisa R, Bisagni G, Flora M, Bassano C, Martella E, Lagrasta C, Nizzoli R, Personeni N, Leonardi F, Cocconi G, Ardizzoni A. Evaluation of HER-2/neu amplification and other biological markers as predictors of response to neoadjuvant anthracyclinebased chemotherapy in primary breast cancer: the role of anthracycline dose intensity. Am J Clin Oncol. 2006; 29:171-177.

30. Hammond ME, Hayes DF, Wolff AC, Mangu PB, Temin S. American society of clinical oncology/college of american pathologists guideline recommendations for immunohistochemical testing of estrogen and progesterone receptors in breast cancer. J Oncol Pract. 2010; 6:195-197.

31. Yaziji H, Goldstein LC, Barry TS, Werling R, Hwang H, Ellis GK, Gralow JR, Livingston RB, Gown AM. HER-2 testing in breast cancer using parallel tissue-based methods. JAMA. 2004; 291:1972-1977. 